\title{
Experimental Study of Vitiation Effects on Flameholding in a Hydrocarbon Fueled Dual-Mode Scramjet Combustor
}

\author{
A Thesis \\ Presented to the Faculty of the \\ School of Engineering and Applied Science \\ University of Virginia
}

\begin{abstract}
In partial fulfillment
of the requirements for the degree of

Master of Science in

Mechanical and Aerospace Engineering

by
\end{abstract}

Benjamin J. Tatman

May 2012 


\section{Approval Sheet}

The thesis is submitted in partial fulfillment of the

Reqruiements for the degree of

Master of Science in

Mechanical and Aerospace Engineering

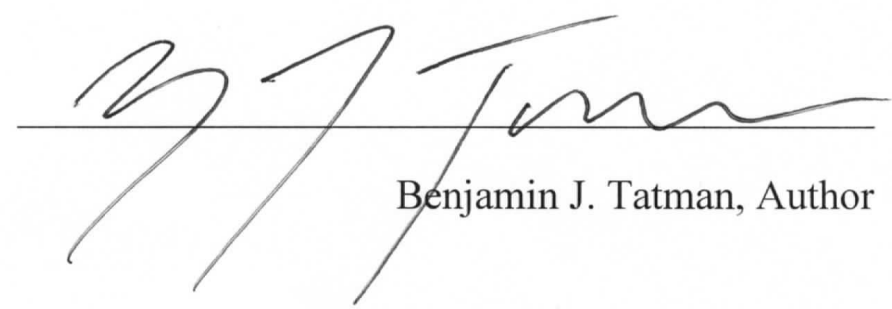

This thesis has been read and approved by the examining Committee:

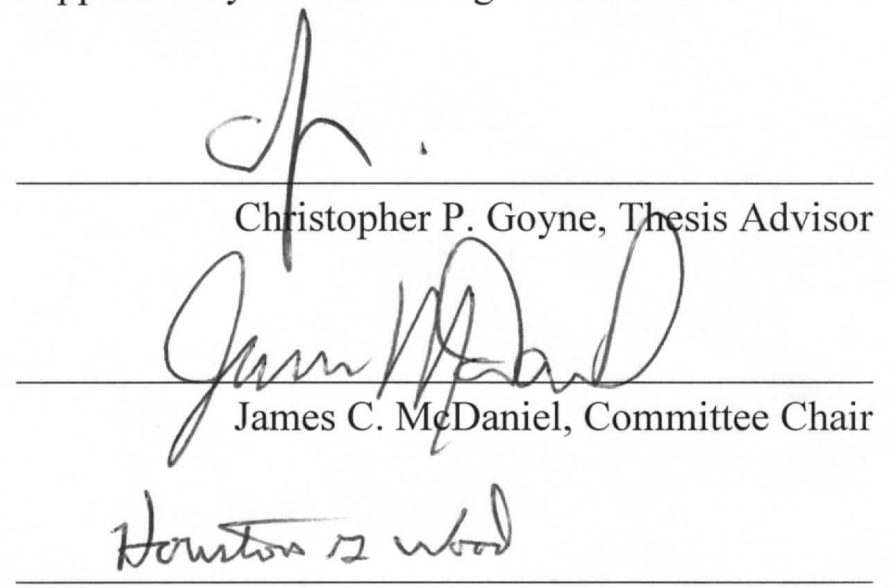

Houston G. Wood, Committee Member

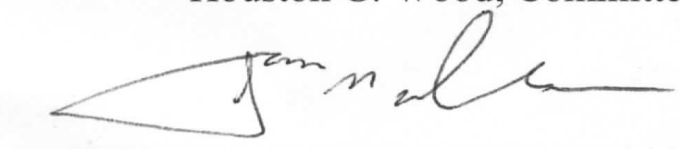

James M. Donohue, Committee Member

Accepted for the School of Engineering and Applied Science:

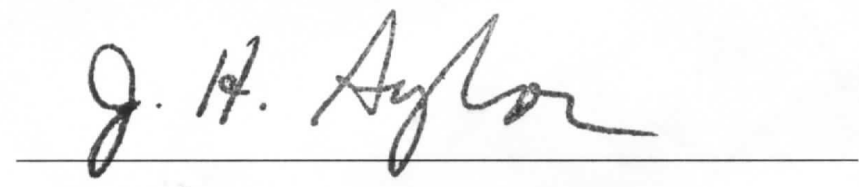

James H. Aylor, Dean, School of Engineering and Applied Science

May 2012 


\begin{abstract}
Wind tunnel tests were performed to determine the effect of vitiation on flameholding limits in a hydrocarbon fueled dual-mode scramjet flameholder. The test medium was generated with clean-air and with air vitiated with $6.7 \%$ water by mole in order to examine the effect of hydrogen combustion vitiation on flameholding. The tests were performed in a direct-connect configuration, with a rectangular divergent combustor, a directly fueled cavity flameholder and a constant area isolator section. Ethylene was chosen as the test fuel in order to simulate the use of a hydrocarbon jet fuel. An air throttle was used as an independent back pressure source to hold the position of the shock train constant, minimizing the variation of the isolator flowfield so that the sensitivity of flameholding to chemical kinetics could be studied. Both the test medium total temperature and fuel equivalence ratio, in separate tests, were lowered until combustor blowout was achieved. This enabled a determination of the lower limits of simulated flight Mach number and lean fuel operation, respectively. There was no distinguishable difference between flameholding limits in the clean-air and vitiated runs. This indicates that, when evaluating combustion heated wind tunnel test data on flameholding limits in directly fueled cavity flameholders with constant combustor pressure, there is no need to compensate for vitiation effects. While many investigators have examined the effect of vitiation on combustor performance, there have been no studies published in the literature on the effects of vitiation on flameholding limits. The data also provides a flameholding limit test case, important for improving model prediction of operating limits.
\end{abstract}




\section{Acknowledgements}

This work was funded by the United Technologies Research Center. The author would like to thank especially Roger Reynolds and Robert Rockwell of the University of Virginia for long hours and critical assistance in preparing and performing the experiment, and interpreting data. The author would also like to thank James Donohue of the UTRC, as well as Chris Goyne and James McDaniel of the University of Virginia for project direction and support. The author would also like to thank Roland Krauss of the University of Virginia for assistance performing the experiments, as well as Harsha Chelliah of the University of Virginia and Mark Gruber of the Air Force Research Laboratory for helpful discussion. 


\section{Table of Contents}

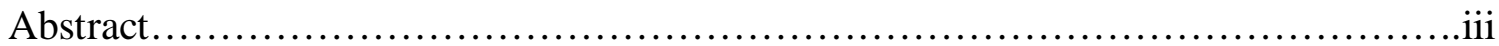

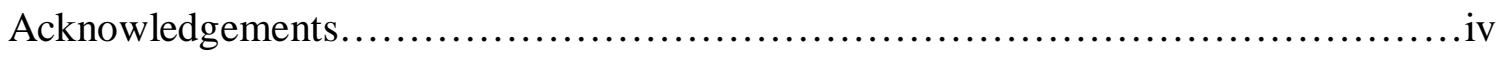

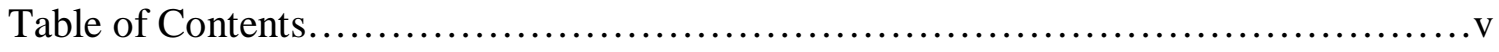

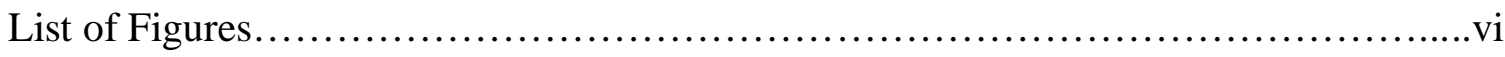

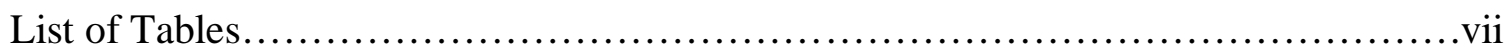

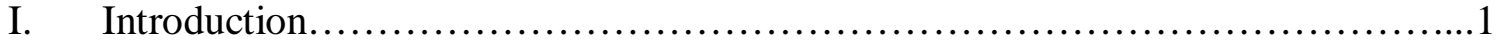

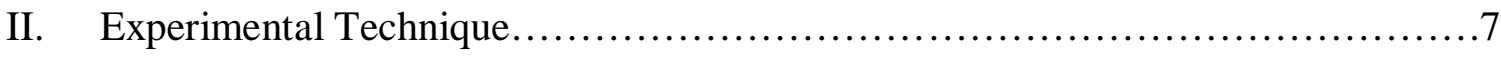

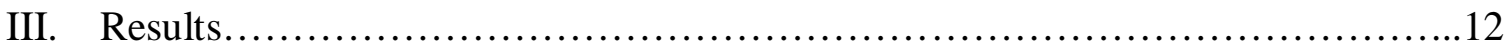

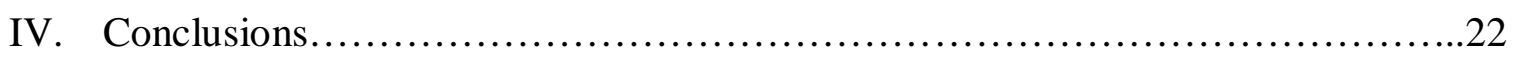

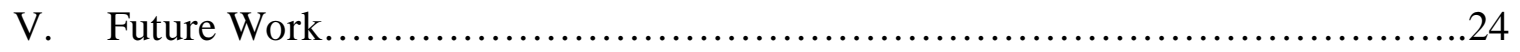

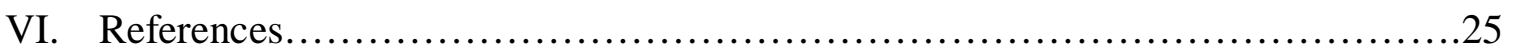

Appendix A: Fuel System.................................................27

Appendix B: Cavity Fuel Injector Drawings....................................29

Appendix C: Instrumentation List.............................................. 32 


\section{List of Figures}

Figure 1 - Schematic of the Cavity Fuel Injector Flowpath...........................8

Figure 2 - Wall pressure scans of back pressure control with air throttle................12

Figure 3 - Images of Combustion in Cavity Flameholder.......................... 14

Figure $4-$ Wall pressure scans of the effect of combustion and vitiation................15

Figure 5 - Wall pressure scans of combustion repeatability $\ldots \ldots \ldots \ldots \ldots \ldots \ldots \ldots \ldots \ldots$

Figure 6 - Flameout test data chart............................................. 18 


\section{List of Tables}

Table 1 - Chocked Orifice parameters and mass-flow-rate uncertainties................10

Table 2 - Test Conditions...................................................... 11 


\section{Chapter I: Introduction}

Dual-mode scramjets are being developed as a promising propulsion technology for practical high speed and trans-atmospheric flight. To better understand the technology's mission capabilities, it is necessary to determine the limits on possible flight trajectories. Such trajectories are often bounded by thermal and structural limits and by the engine's ability to sustain steady combustion. Flameholding is particularly important in that it is necessary for thrust production. Wind tunnel investigations are useful as a low cost alternative to flight testing for determining an engine's flameholding limits and other performance parameters. It is difficult however to reproduce a hypersonic vehicle's high enthalpy engine flow conditions on the ground. In heating the air flow, many tunnels introduce vitiation into their test medium, and the effect of this vitiation on experimental data must be understood before extrapolations to flight are possible.

Flameholding is a difficult problem in scramjets because, in supersonic combustors, mixing, ignition and combustion must occur within a very short residence time, on the order of a millisecond [1]. This problem applies especially to hydrocarbon fuels such as JP-7, an often used jet fuel. Such fuels consist of long chains of hydrogen and carbon molecules with longer dissociation times than smaller molecules (such as hydrogen), and thus have long ignition delay times, often exceeding a millisecond. For this reason, supersonic combustors that burn hydrocarbons usually have a recessed cavity in the wall of the engine to provide a low speed recirculation zone, increasing the residence time of the fuel. Extensive testing has been done on burning hydrocarbons in cavity fueled combustors, evaluating their operability and performance $[2,3,4,5]$. Studies on flameholding limits by Lin et. al. and Rasmussen et. al. have shown that cavity 
flameholders should be functional over a promising range of fueling conditions. The investigators showed this by decreasing and increasing fuel equivalence ratio until blowout at various test medium total temperatures [2,3]. Equivalence ratio is the current fuel to oxygen ratio, divided by the stoichiometric fuel to oxygen ratio. Flameholding tests are also being performed at the UTRC Scramjet Test Facility in a directly fueled cavity flameholder, by lowering the test air stagnation temperature until blowout.

Although different from the more prevalent method of varying equivalence ratio until blowout, changing freestream flow conditions such as stagnation temperature is relevant to a scramjet's flight trajectory envelope, as it provides a lower limit for flight Mach number.

A previous study on flameholding, performed by Zukoski and Marble [6], proposed that blowout occurs when the residence time of the fuel in the reaction zone is equal to the ignition delay time of the fuel. Based on this theory, many experiments have been dedicated to defining a stability parameter that will determine when blowout will occur, usually depending on the engine geometry and on flow conditions. If the stability parameter accurately describes the flow physics, then this analysis can be used to predict the behavior of larger scramjet engines, based on a characteristic flameholder length, which is included in the stability parameter [7]. Ozawa et. al. and Huelmantel et. al. have compiled many data sets on flameholding in premixed flames, and have defined stability parameters that make reasonably accurate predictions to flameout behavior in high speed combustors $[8,9]$. Unfortunately, these stability parameters have been shown to be inaccurate for non-premixed flames [7], and scramjet combustors are essentially non-premixed. Unlike premixed flows, the position of the reaction zone in non premixed 
flows depends on where the fuel injection is relative to the recirculation region. The position of the reaction zone changes factors that are critical in flameholding, such as air entrainment, and the temperature of the reaction zone. Using cavity flameholding limit databases by Rasmussen et. al. [3] and Gruber et. al. [4], Driscoll et. al. have successfully correlated a stability parameter for non premixed cavity flows, although they noted that the correlation depends on air entrainment rates in the cavity, and the fuel flow path to the reaction zone [7]. They emphasize that more research is required to help define these characteristics for various non-premixed cavity configurations. Further flameholding tests are required to provide validation for the numerical models developed in these studies.

To perform relevant flameholding tests on the ground, it is necessary to simulate the high enthalpy of hypersonic flight. The simplest and most common method to achieve this is using a vitiated heater, which uses combustion to heat the airflow. However, this contaminates the flow with combustion products that are not present in atmospheric air in similar quantities. For example, the UTRC Scramjet Test Facility burns hydrogen in the heater section, producing a test medium of air at $1200 \mathrm{~K}$ with a composition of $12 \%$ water by mole. To extrapolate ground test data obtained in vitiation heated facilities to flight, it is necessary to understand the effects of this vitiation on flameholding and combustion.

Combustion vitiation can affect both the thermodynamics of the flow and the chemical kinetics of combustion. Water vapor can affect the chemistry of combustion by acting as a third body in the reaction, recombining reaction products, and breaking the reaction chain by forming $\mathrm{HO}_{2}$, a long-lived radical. This has the effect of suppressing 
the reaction rate. Chinitz et. al. [10] showed numerically that water vapor can increase the ignition delay time of ethylene by $40 \%$ at a test medium temperature of $1000 \mathrm{~K}$, with an increasing trend as temperature decreases. Fuller et. al. have compared numerical and experimental studies of water vapor vitiation effects on decane Bunsen burner flames [11]. The results showed that the model over predicted flame speed when comparing to experimental results, unless it treated the water as a reactive third body. Because of the difference in heat capacity between vitiated and clean-air, and because steam absorbs heat when it dissociates at high temperatures, water vapor can also affect the thermodynamics by decreasing the pressure and temperature rise from combustion [12]. Rockwell et. al. showed experimentally the effects of vitiation by burning hydrogen fuel with and without water vapor and carbon dioxide in a dual-mode scramjet flowpath. They saw as much as $20 \%$ reduced combustor pressure at $6 \%$ water by mole [13]. However, in the same tests, there was very little additional reduction in combustor performance with water levels higher than $6 \%$. The effects observed were attributed to both thermodynamic and chemical kinetic effects of vitiation. As flameholding relies directly on ignition delay time, which in turn relies on the thermodynamics and chemical kinetics of the fuel-air system, these studies imply that water vapor may have a significant effect on flameholding limits. This justifies the need for experimental research, to study the magnitude of the effect of vitiation on flameholding, and whether it must be compensated for, or if it can simply be ignored.

In flameholding tests, it can be difficult to determine the mechanism of flameout. In a standard fueling configuration, which consists of main duct combustion with or without direct cavity fueling, a thermal throat forms downstream due to heat release in 
the combustor. This throat causes a pressure rise that pushes the shock train into the isolator, resulting in dual-mode operation of the scramjet. In flameholding tests, it is difficult to tell whether flame extinction was caused by a change in reaction kinetics, or because reduced combustion eliminated the thermal throat, thus causing the collapse of the shock train and a large reduction in combustor pressure, and increase in combustor speed. As the shock train is relatively unsteady, this can cause a lack of repeatability in experimental results. However, a throttle can be used to provide the same back pressure as the thermal throat, thus holding the shock train in a constant position, without the need for mainstream combustion. Thus, tests can be performed that specifically study the sensitivity of flameholding limits to the chemical kinetics of combustion. Also, the throttle should have the added benefit of making the tests more repeatable. The UTRC Scramjet Test Facility uses a mechanical throttle to achieve back pressure control. Lin et. al. have achieved independent back pressure control by means of air injection downstream of the flameholding cavity in a hydrocarbon fueled scramjet combustor, studying lean and rich blowout limits. Neither of these experiments was able to study the effect of vitiation on flameholding limits.

Therefore, the purpose of this study is to investigate the effects of vitiation on flameholding limits in a hydrocarbon fueled dual-mode scramjet. The results are intended to aid interpretation of test data in any hydrogen combustion heated facility. However, the experiment was developed with the intention of complementing a companion, direct-connect, hydrocarbon fueled scramjet experiment in the UTRC Scramjet Test Facility. This experiment will be reported separately. Therefore, the objectives of this study are to: 
1. Design, manufacture and install a hydrocarbon fueled dual-mode scramjet, with lineage to UTRC Scramjet Test Facility flowpath, and with independent back pressure control for testing at in the University of Virginia Supersonic Combustion Facility,

2. Confirm that the throttle is capable of positioning the shock train at a specified location in the scramjet isolator throughout testing,

3. Demonstrate flameholding capability with hydrocarbon fuel in a directly fueled cavity flameholder, and

4. Examine the effects of water vapor vitiation on low temperature flameholding limits in a hydrocarbon fueled cavity flameholder, with the shock train decoupled from combustion

This paper begins with a description of the facility, flowpath, fuel system, air throttle and instrumentation. The results include axial pressure distributions showing shock train throttle control, and pressure rise due to combustion and vitiation, as well as flameout limit data, taken with both clean-air and water vapor vitiation. The results are intended to provide information for other facilities, to help them determine if the effects of vitiation must be compensated for, and if so, to what extent. The present study is novel because there has been no published experimental data regarding vitiation effects on scramjet flameholding limits. It is also represents an important test case, studying the chemical kinetic dependence of flameholding, and providing data for model validation. These models are important for developing flameout prediction tools, thus aiding the sizing of flameholders in larger scramjets. Also, the use of ethylene, a more complex molecule than hydrogen, provides a stepping stone for modelers, with the goal of eventually simulating the even more complex chemistry present in typical jet fuel combustion. 


\section{Experimental Technique}

The experiments were conducted using the University of Virginia Supersonic Combustion Facility. The facility air was supplied by a compressor that allows for continuous operation. It was sent through a dryer and then electrically heated by a $300 \mathrm{~kW}, 14$ stage resistance heater. This makes it possible to generate freestream air with no vitiation present. The test air stagnation temperature can be maintained as high as $1200 \mathrm{~K}$ in this heating system. The stagnation temperature can also be reduced during wind tunnel runs, although it takes approximately one half hour to reduce to room temperature. The facility has the capability to inject up to $12 \%$ water in the form of steam and $4 \%$ carbon dioxide by mole, in order to match the freestream air conditions typical in combustion heated facilities. Make up oxygen can also be added to return the test medium to standard atmospheric levels of $21 \%$. The steam and oxygen were injected in the heater section to allow for mixing in the free stream before entering the nozzle. The steam was injected where the air is already partially warmed, so that no condensation formed.

The flowpath shown in figure 1 includes the cavity flameholder and fuel injector designed for this study. Machine drawings of the cavity fuel injector wall are presented in Appendix B. It takes lineage from the Hifire flight 2 flowpath [9], and UTRC's Scramjet Test Facility. The flowpath has the same profile as the above flowpaths, with dimensions scaled by the duct height. However, the width of the flowpath is different, even with scaling, as is the exact location of the throttle device. The flowpath begins with a $2 \mathrm{D}$ contoured Mach 2 nozzle with a 1.5 inch wide by 1 inch high exit. There is a 13.1 inch constant area isolator section followed by a 2.9 degree divergence beginning 
upstream of fuel injection. The divergent wall includes the cavity flameholder with upstream, downstream, and direct cavity fueling capability. The cavity is 0.356 inches deep with an L/D ratio of 5.25, and a closeout angle of 22.5 degrees. For these experiments, ethylene fuel was injected directly into the cavity through five equally spaced sonic nozzles, 0.205 inches apart, diameter 0.021 inches, halfway along the cavity ramp closeout, parallel to the cavity floor. The nozzles have $60 \%$ more spacing from the side wall than the nozzle to nozzle spacing in an attempt to minimize side wall effects on flameholding. The fuel was ignited with a hydrogen-oxygen detonation driven igniter that injects high pressure, high temperature combustion product from the upstream end of the floor of the cavity. The ethylene was heated upstream of the fuel control valve to about 40 degrees $\mathrm{C}$ to ensure that it did not condense anywhere in the lines, although it cooled to room temperature before the point of injection. The exact range of fuel stagnation temperatures is given in table 2. Also, the fuel control valve and a regulator located just downstream of the fuel farm were both wrapped in heat tape to prevent the mechanical parts from freezing due to the fuel pressure drop at these locations. A more complete description of the fuel system is given in appendix A.

An air throttle was chosen to provide back pressure control. A portion of the air from the main compressed air supply was taken and injected in the divergent section of the combustor, 17.1 inches downstream of fuel injection, from both side walls. The injector is a rectangular slot, dimensions 1.61 by 0.0625 inches, covering the entire height of the duct at this axial location, and is designed to be sonic. The position is displayed in figure 1 . 


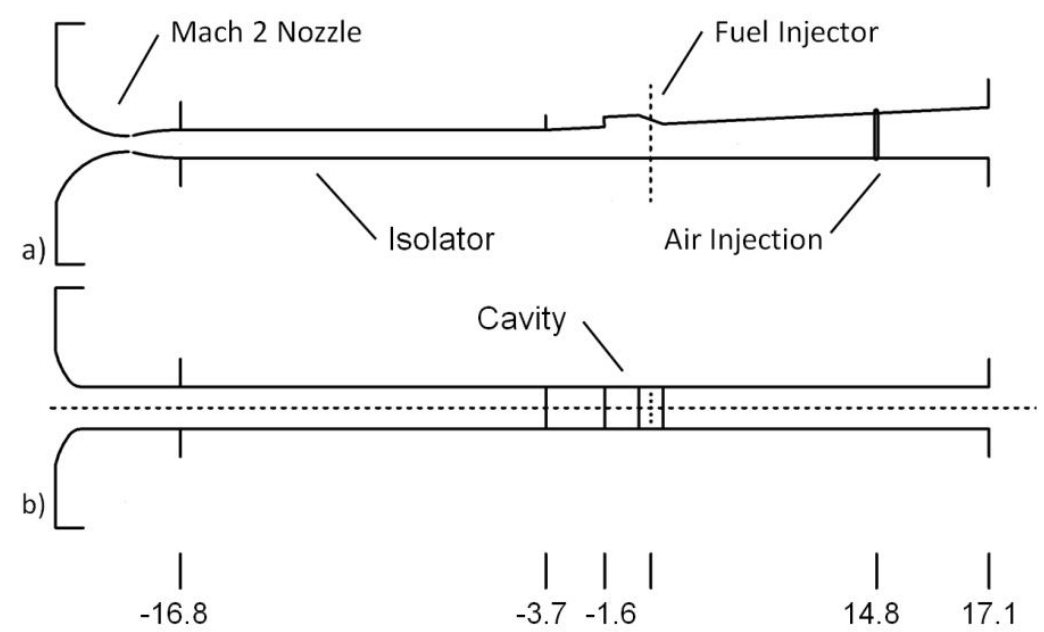

Fig. 1 UVASCF flowpath with cavity fuel injector a) Side view and b) top view with key points labeled and distances from fuel injector given in inches.

The flowpath was instrumented with low frequency pressure taps and thermocouples for pressure and temperature measurement. Forty pressure taps and ten thermocouples are spread along the centerline of the fuel injection side of the flowpath. Six pressure taps located on the cavity floor and just downstream of the cavity are placed in symmetrical pairs about the centerline, 0.626 inches apart. Pressure scans were an average of $10 \mathrm{~Hz}$ measurements taken over a period of 2 seconds. Omega thermocouples and Setra pressure transducers are used. All pressure and temperature measurements are read in through two National Instruments SCXI-1001 chassis, one SCXI-1000 chassis, and a Pressure Systems PSI Netscanner 98RK with three 9816 pressure scanner modules and a 9046 temperature scanner. Side windows in the combustor allowed live observation of flame and extinction through a video camera which is monitored from the control room. Actual time of flame extinction is taken from a wall temperature measurement in the cavity, which was seen to drop off dramatically within a second of flame extinction. This was considered to be a sufficiently accurate measurement, as 
tunnel conditions were varied relatively very slowly, taking 20 minutes to achieve a single flameout point. A detailed list of tunnel instrumentation is given in Appendix C.

Flow rates of fuel, water, oxygen, and test medium air were set using orifice plates, nozzles and isentropic choked flow relations, starting with monitored values of stagnation temperature and pressure. The ranges covered for each flow rate, as well as the uncertainties and various other flow parameters are listed in tables 1 and 2. Manufacturer values of uncertainty were used for pressure transducers and thermocouples. Mass flow uncertainty was calculated from the uncertainty in the orifice area, discharge coefficient and stagnation temperature and pressure readings.

Table 1 Choked orifice parameters and calculated mass-flow-rate uncertainties

\begin{tabular}{lcccc}
\hline & Facility Nozzle & $\mathrm{H}_{2} \mathrm{O}$ & Makeup $\mathrm{O}_{2}$ & Fuel \\
\hline Area, $\mathrm{mm}^{2}$ & $541.9 \pm 0.2$ & $2.48 \pm 0.2$ & $2.3 \pm 0.1$ & $1.12 \pm 0.04$ \\
Discharge Coefficient & $0.99 \pm 0.01$ & $0.95 \pm 0.03$ & $0.95 \pm 0.03$ & $0.38 \pm 0.04$ \\
Uncertainty in mass flow, \% & \pm 1.3 & \pm 3.4 & \pm 5.4 & \pm 6. \\
Uncertainty in EQ ratio, \% & - & - & - & \pm 1.2 \\
\hline \hline
\end{tabular}

The experiment was conducted by first setting the facility stagnation temperature and pressure at $1200 \mathrm{~K}$ and $330 \mathrm{kPa}$. The air throttle was then activated, and the shock train was positioned approximately 3.3 inches through the isolator, from the nozzle exit. This position was chosen to provide primarily subsonic combustion, but not so far upstream that there would be danger of unstarting the nozzle. The fuel stagnation pressure was then set at one of several chosen test values, the range of which is shown in Table 2. The equivalence ratios centered on a phi of 0.1 , which was predicted to be close to a stoichiometric level for the cavity. This was based on preliminary data from the UTRC Scramjet Test Facility, which assumed that the vertex of the low temperature limit curve was near stoichiometric condtions. The stagnation temperature was then 
decreased, while constantly adjusting the air throttle to keep the shock train in position, until flameout occurred. The same test was then run with $6.7 \%$ water. This number was chosen to simulate the amount of water that would be present in a vitiated wind tunnel at our predicted temperature, $800 \mathrm{~K}$, which was based on preliminary results from the UTRC Scramjet Test Facility. The shock train was positioned after the water level is set. This vitiation level was chosen to simulate the level of water that would be present in a vitiated heater facility at the predicted flameout temperature. The flameout temperature was predicted to be approximately $800 \mathrm{~K}$, based on preliminary data from the UTRC Scramjet Test Facility. Also, two lean blowout limits were taken for clean-air, and one for the vitiated case, so that the results may also be applied to lean blowout limit tests at other facilities. At flameout, stagnation values of tunnel, fuel, steam, and oxygen temperature and pressure were recorded, to determine the mass flow rates of each and the calculated equivalence ratios at flameout.

Table 2 Test Conditions

\begin{tabular}{lccc}
\hline Parameter & Air & Water & Fuel \\
\hline & & & \\
Total Pressure, kPa & $325-327$ & $684-922$ & $188-2845$ \\
Total Temperature, $\mathrm{K}$ & $1201-553$ & $423-436$ & $284-307$ \\
Mach Number & 2.02 & 1 & 1 \\
Static Pressure, $\mathrm{kPa}$ & 41 & $371-500$ & $105-1583$ \\
Static Temperature, $\mathrm{K}$ & $725-312$ & $364-376$ & $254-274$ \\
Velocity, m/s & $536-352$ & $471-479$ & $306-317$ \\
Mass Flow Rate, g/s & $196-299$ & $11.8-15.6$ & $0.178-2.631$ \\
Equivalence Ratio & - & - & $0.013-0.14$ \\
\hline
\end{tabular}




\section{Results}

The following section describes the success of the air throttle and flameholder from a design perspective, and discusses the result of the flameholding limit tests and vitiation effects. The air throttle was tested first and the results are displayed in figure 2 , showing axial pressure distributions. The pressure is normalized by the average nozzle exit pressure, $\mathrm{P}_{\text {ref, }}$ while the axial distance is normalized by the inlet height of the duct, $\mathrm{H}$. With the air throttle turned off ( 0 psi control pressure), the pressure stays relatively constant through most of the flowpath, except for weak waves in the isolator and low strength shocks and expansions propagating from the edges of the cavity. Near the exit, starting at 4 duct heights downstream of fuel injection, ambient back pressure creates a shock train that increases the wall pressure gradually towards the exit. When the air throttle is turned on, there is blockage due to the injected air, increasing back pressure and pushing the leading edge of the shock train into the isolator.

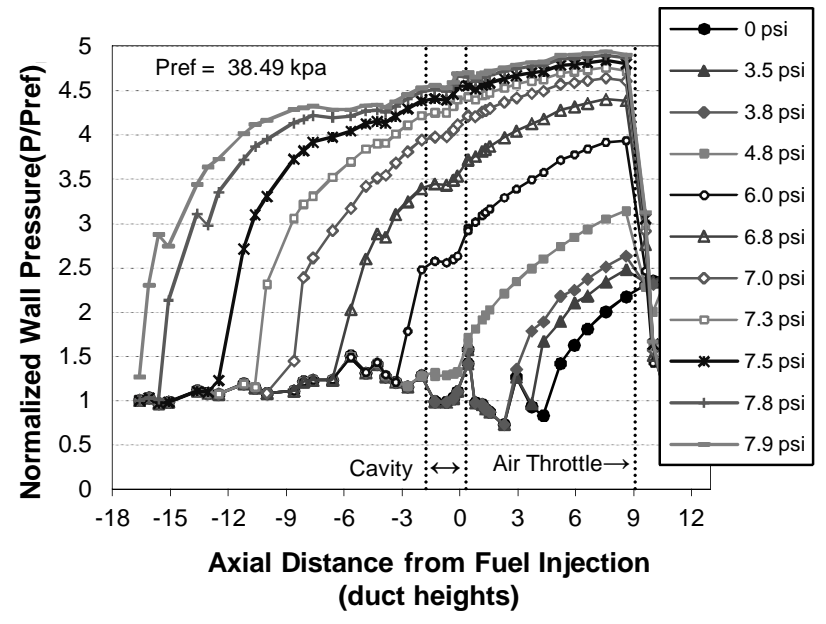

Fig. 2 Wall pressure distributions showing shock train control at various air throttle control pressures. Increasing control pressures correspond to increasing air injection flow rates. Axial distance is given in isolator duct heights $(\mathrm{H}=\mathbf{2 . 5 4} \mathrm{cm})$. Cavity and air throttle injection are marked. 
A requirement for the flameholding tests was to achieve primarily subsonic combustion, and thus simulate the dual-mode operation of the dual-mode scramjet. According to a one-dimensional control volume analysis of this isolator following Heiser and Pratt [17], the combustor air flow is subsonic when the ratio of the combustor pressure and the nozzle exit pressure is greater than or equal to approximately 3 , for both clean-air and vitiated cases. A pressure tap 13 duct heights upstream of fuel injection was chosen as the anchor position for the leading edge of the shock train, so as to ensure subsonic combustion, but not be in danger of unstarting the facility nozzle. As shown in the figure, for this shock train position, the pressure just upstream of the cavity is almost 4.5 times the nozzle exit pressure, indicating that the cavity air flow is at least primarily subsonic, although the one-dimensional calculation does not truly represent the threedimensional flow.

Once the operation of the air throttle was characterized, the behavior of the flameholder and combustion environment was examined. This is important because, as discussed in the literature, flame out depends on the position and characteristics of the flame. This information may determine whether these results are relevant for interpreting data produced on a flowpath at a different facility. In these experiments, the combustor was able to achieve ignition and stable combustion at a total temperature of $1200 \mathrm{~K}$ and total pressure of 330kpa, with an equivalence ratio of approximately 0.12 . Lean ignition limit was not studied, although ignition was possible as low as an equivalence ratio of 0.06 . The low temperature ignition limit was $1150 \mathrm{~K}$ at an equivalence ratio of approximately 0.12 . The large difference between this ignition limit and the low temperature flameholding limit, discussed later on, is most likely due to the 
walls of the combustor being preheated during flameholding. The cavity flame was stable with no strong visible oscillations. These oscillations are often present in other facilities, and can be seen plainly on video. Figure 3 shows the flame luminosity at an equivalence ratio of 0.12 and at an equivalence ratio of 0.016 , the latter being near lean blowout. The images show that there was very little, if any, combustion upstream of the cavity. In the higher equivalence ratio flame, there is flame luminosity well downstream of the cavity, which may imply downstream combustion, or simply that $\mathrm{CH}$ or $\mathrm{C}$ species are still emitting radiation downstream of the cavity. The low equivalence ratio flame shows emissions almost entirely inside the cavity, showing that there is no downstream combustion. Although not pictured, at low stagnation temperatures the visible emissions did not penetrate as far into the main duct, but still extended far downstream of the cavity. Near low temperature blowout, the flame luminosity decreased, the tunnel wall pressure became unsteady, and a small fuel-rich area in the center of the cavity closeout was devoid of flame. There was no evidence of initial blowout and reignition, as sometimes observed in other facilities.
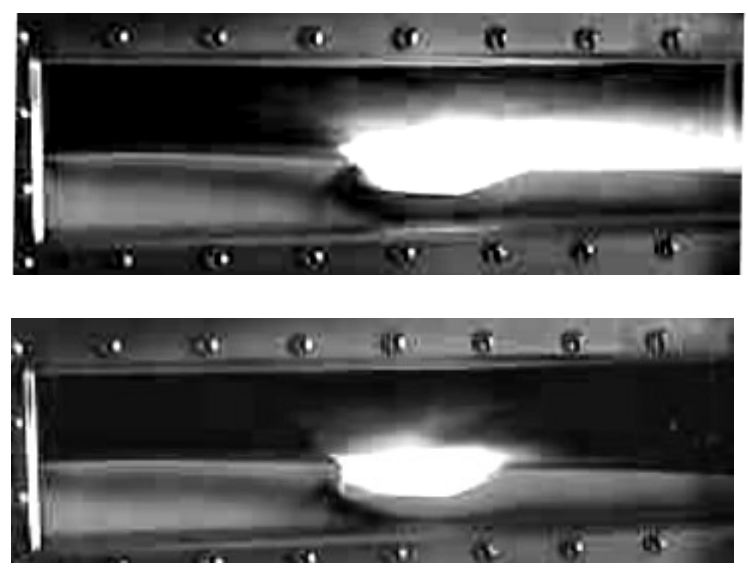

Fig. 3 Ethylene flame in cavity flameholder at equivalence ratios of approximately 0.12 (top) and 0.016 (bottom), both at 1200K. 
Before the effects of vitiation on flameholding limits are examined, the influence of vitiation on the combustion process itself is first discussed. The effect of vitiation on combustor pressure is important in understanding how vitiation might affect flameholding limits. Figure 4 presents axial pressure distributions of combustion with and without vitiation, and fuel-off with and without vitiation. The experiment was conducted by adjusting the fuel and air throttle flow rates so that the shock train was anchored at 13 duct heights upstream of combustion for the clean-air combustion case. The air throttle flow rate was then kept constant, while $12 \%$ water by mole was added, the fuel was turned off, and then the water was removed, taking pressure distributions for each condition. This level of water vapor corresponds to the amount that would be added by hydrogen vitiated heater at a test medium total temperature of $1200 \mathrm{~K}$, which is the initial temperature for this testing. The results show a reduction in pressure with vitiation during both the combustion and fuel-off cases. The fuel-off curve has a more shallow slope with the addition of vitiation, but the same shock train leading edge location. This is due to a reduction in the specific heat of the test medium, which reduces the pressure rise across a shock, thus reducing the slope of the shock train curve. The combustion curve shows the shock train move downstream and a reduced combustor pressure with the addition of vitiation. This is due to the change in specific heat, but also because steam acts as a third body, recombining chemical reactants, and forming the radical $\mathrm{HO}_{2}$, suppressing the flame. These results are a physical verification of the expected thermodynamic and chemical effect of water vitiation discussed in the literature. 


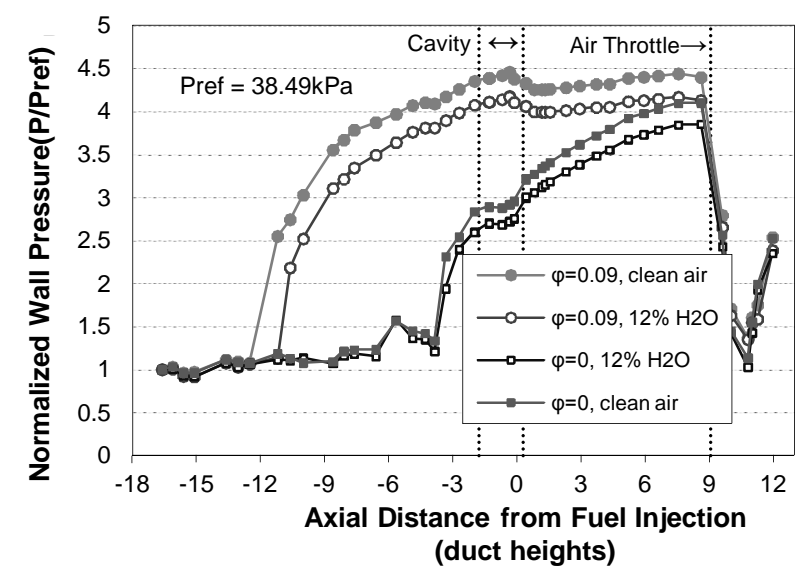

Fig. 4 The effect of directly fueled cavity combustion and test medium vitiation on axial wall pressure distribution. Duct height, $\mathrm{H}=\mathbf{2 . 5 4} \mathrm{cm}$.

It is also necessary to assess the effectiveness of the air throttle in decoupling shock train movement from combustion, and to establish what effect this has on the experimental results. Figure 5 displays axial pressure distributions that show the repeatability of shock train placement during variation in equivalence ratio and test medium total temperature. In this experiment, the air throttle and fuel equivalence ratio were set so that the shock train was positioned at 13 duct heights upstream of fuel injection. Then, both equivalence ratio and test medium total temperature were varied, while adjusting the air throttle control pressure to preserve the location of the shock train. We were able to maintain a consistent shock train position while changing both equivalence ratio and test medium total temperature. This shows that we are able to decouple the movement of the shock train from variations in combustion conditions in both lean blowout tests and low temperature blowout tests. Notably in figure 5, the pressure remains constant in the cavity, even as equivalence ratio and test medium total temperature change, and even though the pressure downstream of the cavity changes. As 
shown in figure 4, adding vitiation lowers combustor pressure, which is a critical parameter for flameholding. The air throttle eliminates the effect this pressure change would have on combustion.

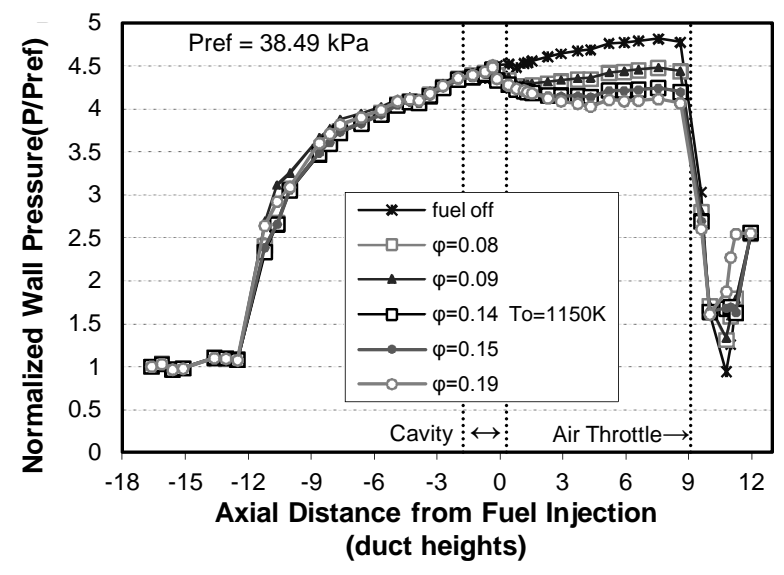

Fig. 5 Pressure distributions of combustion at various equivalence ratios, with shock train position held constant by adjusting air throttle flow rate. Test medium total temperature was held at $1200 \mathrm{~K}$, except for one curve taken at $1150 \mathrm{~K}$. Cavity opening and closeout, and air throttle injection are marked with dashed lines on the figure. Duct height, $\mathrm{H}=$ $2.54 \mathrm{~cm}$.

Figure 6 presents the results of the flameout tests, comparing the vitiated and clean-air data. As in the tests described above, the back pressure device was used to hold the shock train at 13 duct height upstream of fuel injection. However, in this case only $6.7 \%$ water vapor by mole was added to the test medium. This simulated the level of vitiation in a hydrogen combustion heated facility with a stagnation temperature near the expected flameout temperature of $800 \mathrm{~K}$. The figure shows the various flame out points on a graph of equivalence ratio versus test medium total temperature. Three different nominal equivalence ratios, for both the vitiated and clean-air cases each, were studied for low temperature flameout. The equivalence ratio of 0.06 was repeated for both cleanair and vitiated cases. Also, a lean blowout limit value was determined for both clean and 
vitiated cases at $1200 \mathrm{~K}$ total temperature. The vitiated lean blowout limit was repeated for this condition. As can be seen in figure 6, there was one outlier in the vitiation test data. During the repetition of the 0.06 data point in the vitiated case, the flame extinguished at a much higher stagnation temperature than any other low temperature test point. However, the usual visible phenomena preceding flameout, such as an unsteady flame and the small fuel rich area with no combustion, were not visible preceding the flameout. In addition, the data point was subsequently repeated, and the temperature of the flameout grouped well with the previous points taken at the same equivalence ratio. Even though the air throttle keeps the isolator shock train flowfield relatively constant, this outlier is evidence of a smaller amount of unsteadiness still remaining in the isolator flowfield or in the fuel or air throttle systems. This paper is however primarily concerned with the sensitivity of flameholding to chemical kinetics. As shown by characteristics of this flameout point discussed above, this point is clearly not representative of the chemical kinetic limit of combustion.

Mean low temperature limits and $95 \%$ confidence intervals were calculated for both vitiated and clean-air cases. These values are indicated in figure 6. As shown in the figure, the means differ by only $7 \mathrm{~K}$, a difference that can be attributed to the uncertainty expressed in the confidence interval. The lean blowout points also showed no appreciable difference, that could not be attributed to experimental uncertainty. It is evident then, that vitiation has no effect on either the low temperature or low equivalence ratio flameouts, in the case of a directly fueled cavity with a combustion decoupled shock train and a hydrocarbon fuel. 


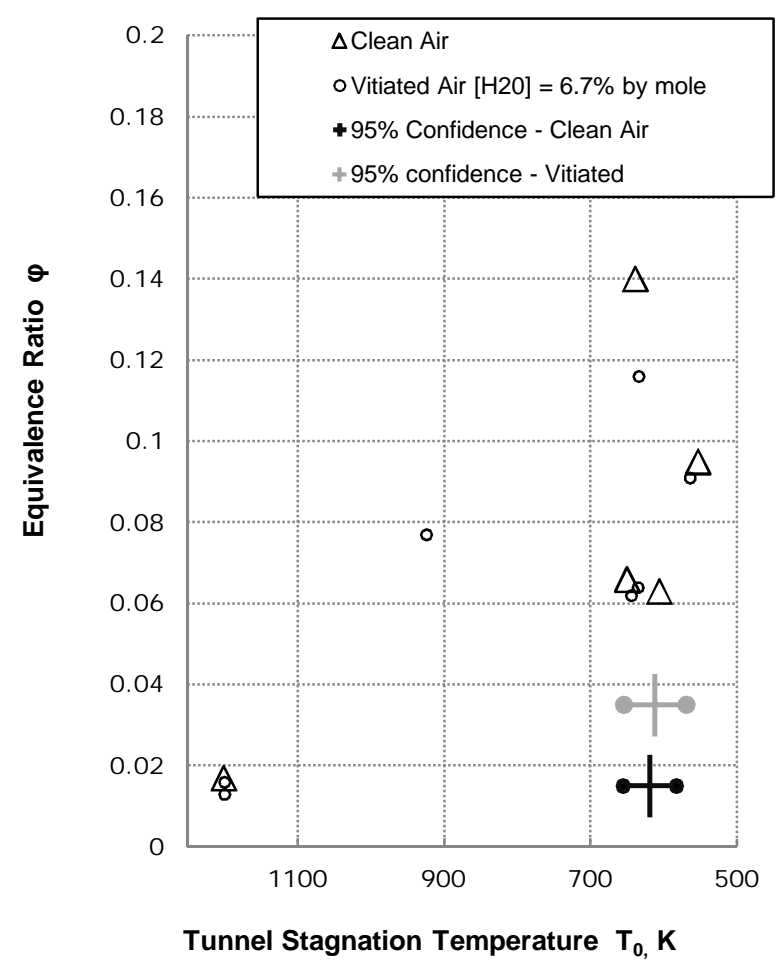

Figure 6. Clean-air and vitiated flameholding limits, including the results of low temperature and lean blowout tests. Includes mean values of low temperature blowouts, with $95 \%$ confidence intervals, for both vitiated and cleanair.

This result is contrary to what may be expected based on the literature. Chinitz et. al. predicted a $40 \%$ increase in ethylene's ignition delay time at $1000 \mathrm{~K}$. Given that flameholding limits depend directly on ignition delay time, it may be expected that vitiation would reduce the ability of the cavity to hold a flame. However, in cavity combustion a portion of the combustion products are recirculated in the cavity. If one assumes that there is no left over fuel or oxygen at stoichiometric conditions, the level of vitiation present in the cavity can be estimated. This rough analysis predicts a level of $11 \%$ water vapor and carbon dioxide by mole in the recirculation zone, during clean-air testing. This vitiation may greatly reduce the impact of the water vapor added during 
testing. This may be one reason we see no difference between the vitiated and clean-air data.

The position of the flame is also important in understanding why there is no effect of vitiation on flameholding limits in this test case. We have so far assumed the flame to be located in the recirculation zone, as opposed to the shear layer. If the flame is sitting on the floor of the cavity, in the recirculation zone, the fuel would have a very long residence time in the reaction zone. In this case, whether the ignition delay time is affected by vitiation or not, the residence time may be long enough that the increased ignition delay time with vitiation would have a negligible effect on flameholding. As discussed above, Chinitz et al. [10] showed numerically that steam can increase the ignition delay time of ethylene by $40 \%$ at a test medium temperature of $1000 \mathrm{~K}$, and a water concentration of $10 \%$. This study unfortunately did not include temperatures as low as the blowout temperatures in this study, but the change in ignition delay would be expected to be slightly higher at these temperatures. Based on the ignition delay correlation by Saxena et. al. [15], near the predicted reaction zone temperature of 700K, an increase in ignition delay time by $40 \%$ only increases the blowout temperature by 10K. This difference would be even smaller if you take into account that the cavity is already vitiated, as discussed above. Such a small deviation in the experimental data may go unnoticed due to experimental uncertainty, which would explain why we see no difference in our vitiated and clean-air data.

If the flame is primarily held in the shear layer, the fuel would have a very short residence time, and the previous two reasons would not be sufficient to explain why we see no difference between the clean-air and vitiated data. Thus, it would be very 
beneficial to know where the flame is being held in our experiments. In high speed images of a hydrocarbon fueled dual-mode scramjet flowpath, Lin. et. al. showed a flame rooted on the cavity floor near fuel injection [5]. Their setup used for obtaining these images was very similar to the configuration used in this paper, including the use of back pressurization, and the position and direction of direct cavity fueling. This would suggest that the flame in our tests was also located in the recirculation zone on the floor of the cavity, although only a reaction visualization technique (such as $\mathrm{OH}$ Planar Laser Induced Fluorescence) would confirm this.

We can at this point say that there is no observable difference between the cleanair and vitiated flameholding data, and that the two factors discussed above are the most likely reasons for this. 


\section{Conclusions}

The effect of vitiation on the flameholding characterists of a hydrocarbon fueled cavity flameholder was studied experimentally using a unique hypersonic ground test facility. The facility was capable of running with clean-air and also with major combustion vitiation species added, at test medium total temperatures up to $1200 \mathrm{~K}$, simulating Mach 5 flight. The following objectives were achieved:

1. A hydrocarbon fueled dual-mode scramjet, with independent back pressurization, was installed at the University of Virginia Supersonic Combustion Facility

2. An air throttle was installed for back pressurization, and was able to hold the combustor pressure and position of the shock train constant during testing

3. Flameholding was achieved in the directly fueled cavity flameholder, with no main duct combustion, using air throttle back pressure

4. The effects of water vapor vitiation on flameholding limits were determined for a directly fueled cavity flameholder, with the shock train decoupled from combustion

The vitiated flameout cases were run with $6.7 \%$ water vapor by mole, which is the amount added by a hydrogen combustion heated facility at a test medium total temperature of $800 \mathrm{~K}$. The effect of vitiation on lean blowout and low temperature flameholding limits was studied, as well as the effect on combustor wall pressure. An air throttle was used to hold the isolator shock train flowfield constant, keeping the shock train position and the combustor pressure constant. The results showed a decrease in wall pressure due to vitiation, but showed no discernible effect on flameholding limits. This 
result is most likely because the long residence time of directly fueled cavity flow means that a moderate change in ignition delay time would have a very small percent change on flameout temperature. Also, combustion products are already recirculated in the cavity from cavity combustion, which reduces the effect of test added vitiation on experimental results. The results have the fortunate outcome that flameholding limit data obtained using hydrogen combustion heated facilities does not have to be altered, and can be considered to be unaffected by water vapor vitiation. Specifically, the results are relevant for dual-mode scramjet facilities using hydrocarbon test fuel, in a directly fueled cavity, with a shock train that has been decoupled by an independent back pressure source. Because the air throttle keeps the shock train flowfield constant, the results also show specifically how chemical kinetics limit flameholding in a cavity flow. This information is critical in developing relevant models for predicting flameholding limits in dual-mode scramjets. The test points had good repeatability, and there were no cases of initial blowout and reignition, making this data a promising source for model validation. 


\section{Future Work}

To further enhance the applications of this experiment, it would be beneficial to repeat the flameholding limit tests with main duct combustion instead of the air throttle. Main duct combustion is more relevant for practical scramjet flight, so the effect of vitiation on such a configuration would likely be of interest to other investigators. Also, it would be beneficial to take $\mathrm{OH}$ Planar Laser-Induced Fluorescence images of the cavity during combustion, with the air throttle turned on, to determine the location of the reaction zone. Knowing the location of the flame would help explain why we observed no difference in flameholding between the clean-air and vitiated test data, and thus would increase our understanding of the complex combustion problem. 


\section{References}

[1] Ben-Yakar, A., and Hanson, R. K., "Cavity Flame-Holders for Igntion and Flame Stabilization in Scramjets: An Overview," Journal of Propulsion and Power, Vol. 17, No. 4, 2001, pp. 869-877. doi: $10.2514 / 2.5818$

[2] Lin, K. C., Tam, C. J., and Jackson, K., "Study on the Operability of Cavity Flameholders Inside a Scramjet Combustor," AIAA paper 2009-5028, 2009.

[3] Rasmussen, C. C., Driscoll, J. F., Hsu, K. Y., Donbar, J. M., Gruber, M. R., and Carter, C. D., "Stability Limits of Cavity-Stabilized Flames in Supersonic Flows," Proceedings of the Combustion Institute, Vol. 30, The Combustion Institute, Pittsburgh, PA, 2005, pp. 2825-2831.

[4] Gruber, M. R., Donbar, J.M., Carter, C. C., and Hsu, K.-Y., "Mixing and Combustion Studies Using Cavity-Based Flameholders in a Supersonic Flow," Journal of Propulsion and Power, Vol. 17, No. 4, 2001, pp.869-877.

[5] Lin, K. C., Tam, C. J., "Flame Characteristics and Fuel Entrainment Inside a Cavity Flame Holder in a Scramjet Combustor," AIAA paper 2007-5381, 2007.

[6] Zukoski, E. E., and Marble, F. E., "Experiments Concerning the Mechanism of Flame Blowoff from Bluff Bodies," Proceedings of the Gas Dynamics Symposium on Thermochemistry, Northwestern Univ., Evanston, IL, 1956, pp. 205-225.

[7] Driscoll, J. F., and Rasmussen, C. C., "Correlation and Analysis of Blowout Limits of Flames in High-Speed Airflows," Journal of Propulsion and Power, Vol. 21, No. 6, 2005, pp. 1035-1044.

[8] Ozawa, R. I., "Survey of Basic Data on Flame Stabilization and Propagation for High Speed Combustion Systems," U.S. Air Force AFAPL Technical Rept. TR-70-81, Wright-Patterson AFB, OH, Jan. 1971.

[9] Huellmantel, L.W., Ziemer, R.W. and Cambel, A.B., "Stabilization of Premixed Propane-Air Flames in Recessed Ducts," Journal of Jet Propulsion, Vol. 27, No. 1, 1957, pp. 31-43.

[10] Chinitz, W., and Erdos, J. I., "Test Facility Chemistry Effects on Hydrogen Flames and Detonations," AIAA paper 95-2467, 1995.

[11] Fuller, C. C., Gokulakrishnan, P., Klassen, M. S., Adusumilli, S., Kochar, Y., Bloomer, D., Seitzman, J., Kim, H. H., Won, S. H., Dryer, F. L., Ju, Y., and Kiel, B. V., "Effects of Vitiation and Pressure on Laminar Flame Speeds of n-Decane," AIAA paper 2012-167, 2012. 
[12] Pellett, G. L., Bruno, C., and Chinitz, W., "Review of Air Vitiation Effects on Scramjet Ignition and Flameholding Combustion Processes," AIAA Paper 20023880, 2002.

[13] Rockwell, R. D., Goyne, C. P., Haw, W., Krauss, R. H., McDaniel, J. C., Trefny, C. J., "Experimental Study of Test-Medium Vitiation Effects on Dual-Mode Scramjet Performance," Journal of Propulsion and Power, Vol. 27, No. 5, 2011, pp. 11351142.

doi: 10.2514/1.B34180

[14] Heiser, W. H., and Pratt, D. T., Hypersonic Airbreathing Propulsion, AIAA Education Series, AIAA, Washington, D.C., 1994, pp. 342-346.

[15] Saxena, S., Kahandawala, M. S. P., Sidhu, S. S., "A Shock Tube Study of Ignition Delay in the Combustion of Ethylene," Combustion and Flame, Vol. 158, No. 6, June 2011, pp. 1019-1031. 


\section{Appendix A: Fuel System}

99.5\% ethylene was used in T size cylinders. A heated regulator was installed outside at the fuel farm, in place of the one used for hydrogen testing. This regulator was wrapped in heat tape, which was set to $50 \%$ power, in order to prevent the ethylene from condensing at this pressure drop location. The regulator was consistently set at $450 \mathrm{psi}$ throughout the testing. The fuel system tubing was then sent indoors. Once there, the tubing was sent through a heat bath, to ensure that the fuel did not condense when passing through the throttle valve. The heat bath included two MGW Lauda K4R circulating heat baths; they send hot water to two copper coils in a trash can, which is filled with water to just over the copper coil heights. The heat baths are not able to set a specified water bath temperature, but are run at full power. The ethylene is also sent through a copper coil in this heat bath. The ethylene temperature is measured by an omega $\mathrm{K}$ type thermocouple just downstream of the bath. The temperature stayed at $40 \mathrm{~K}$ throughout the duration of the testing, with a variance of about 10K. Next, the ethylene enters a settling chamber, followed by the fuel throttle control valve. The throttle valve is set pneumatically from the control room, and is also wrapped in heat tape, to prevent freezing up. The stagnation temperature and pressure of the fuel are measured just upstream of injection into the flowpath, using a setra pressure transducer, and an omega thermocouple. This stagnation temperature varied with flow rate, because the flow rate affects how much heat is transferred from the heat bath to the fuel. The temperature varied between $284 \mathrm{~K}$ and $308 \mathrm{~K}$ during testing. In future testing, the heat baths may not be necessary. It is important to check the temperature and pressure of the gas at this point against a phase diagram of ethylene, to ensure that the ethylene is not in danger of 
condensing in the injection nozzles. The fuel system could be tested without the heat bath, to determine if they are necessary. This would eliminate considerable test preparation time, and complication. 


\section{Appendix B: Cavity Fuel Injector Wall Drawings}

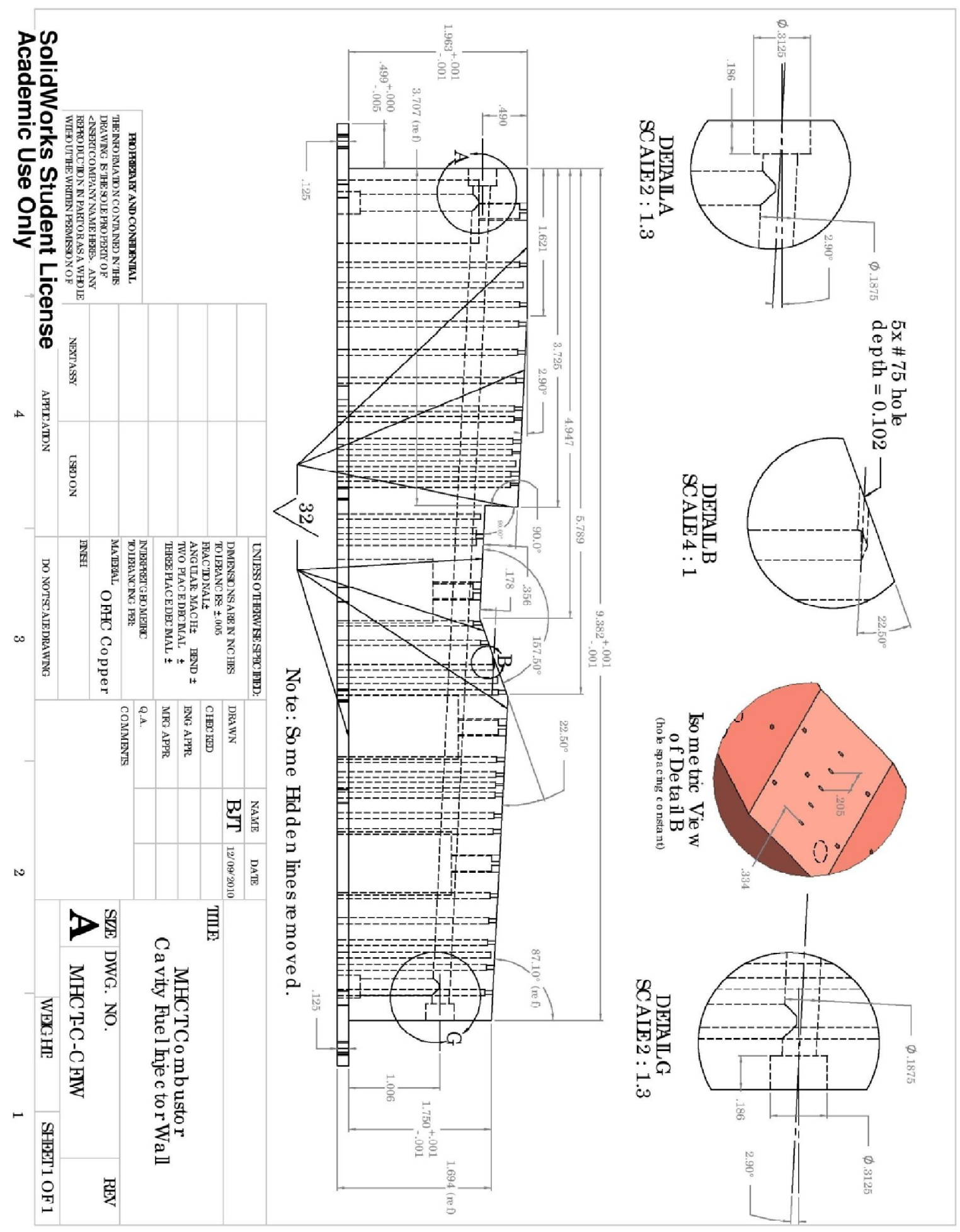




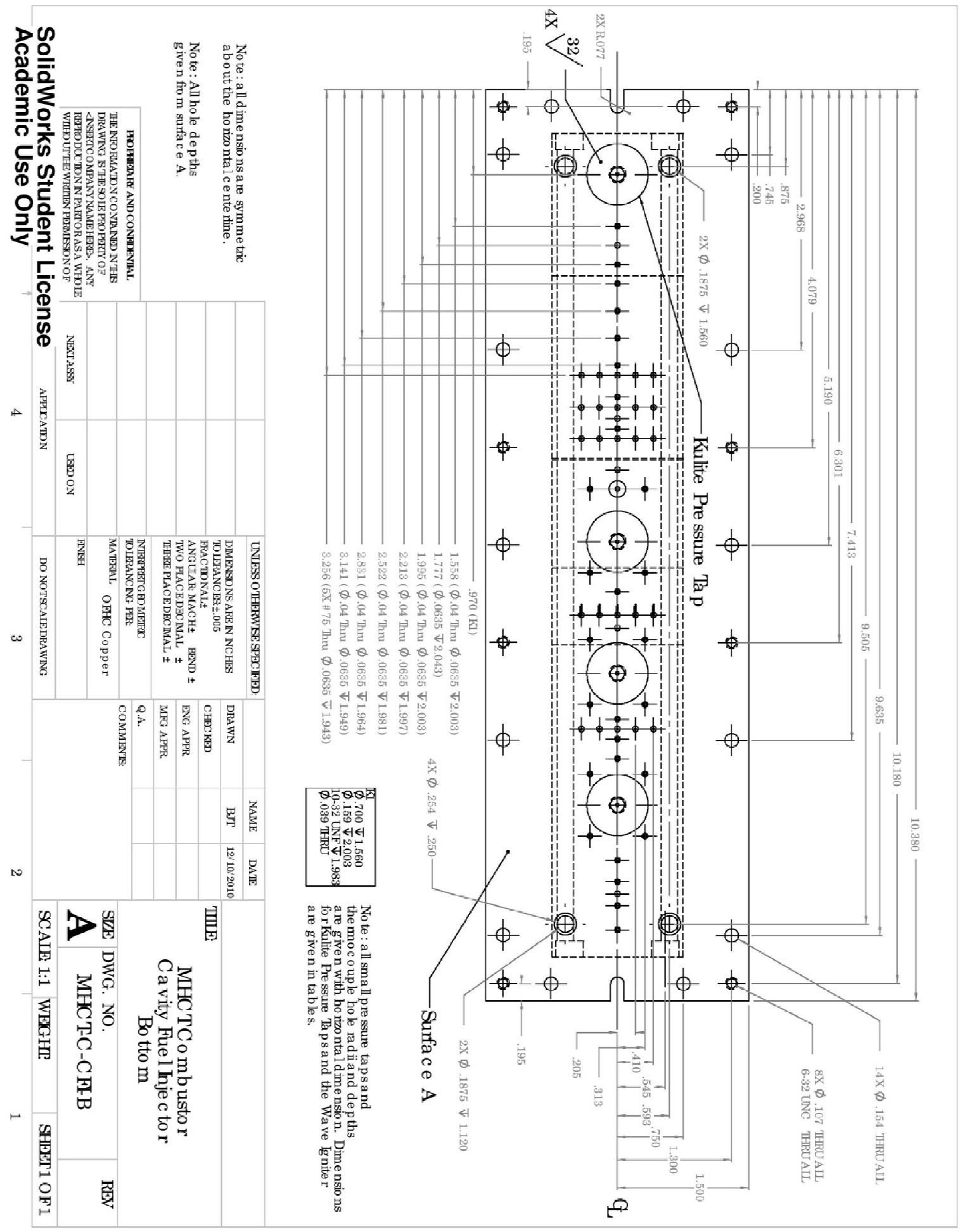




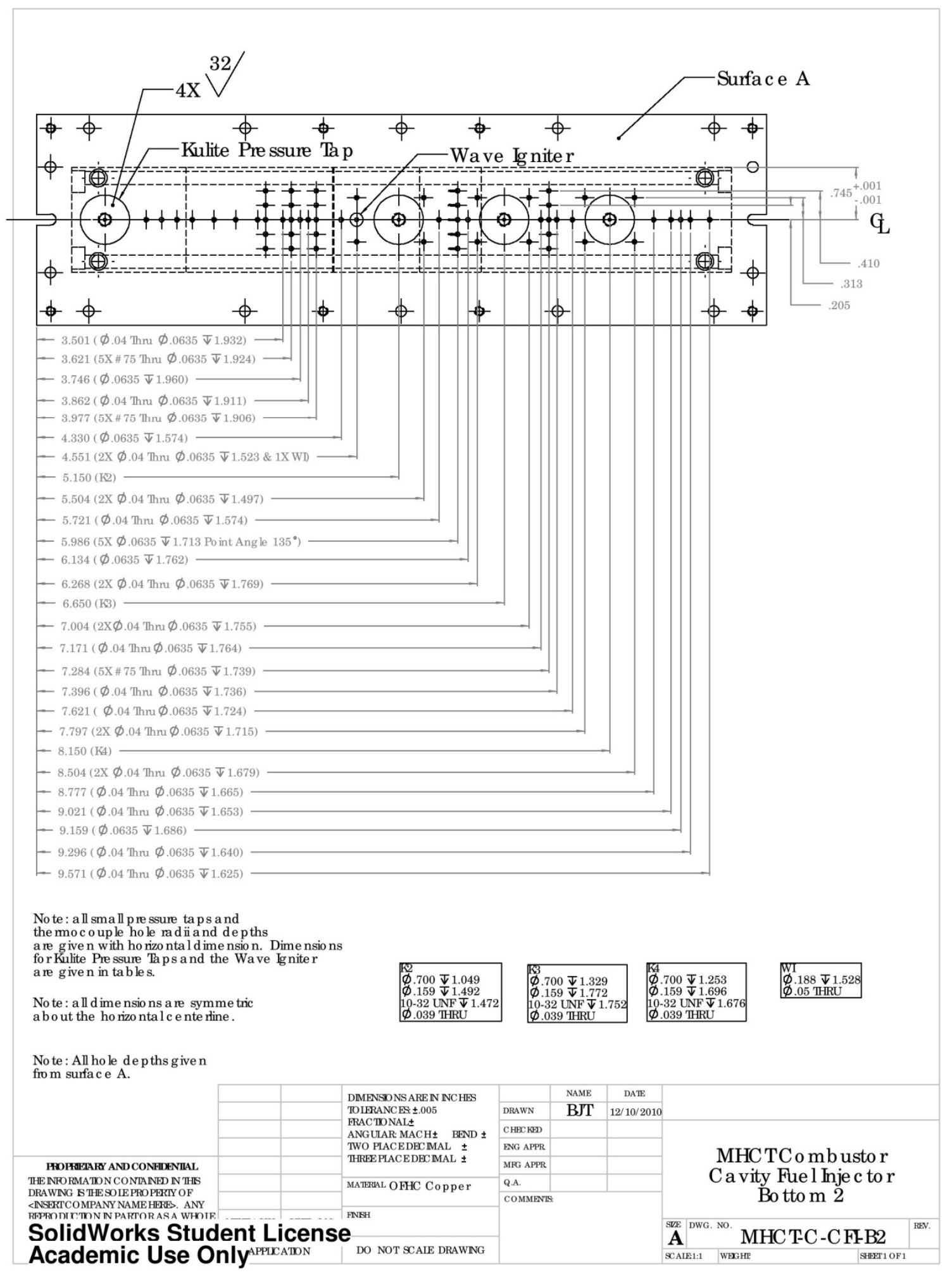




\section{Appendix C: Instrumentation List}

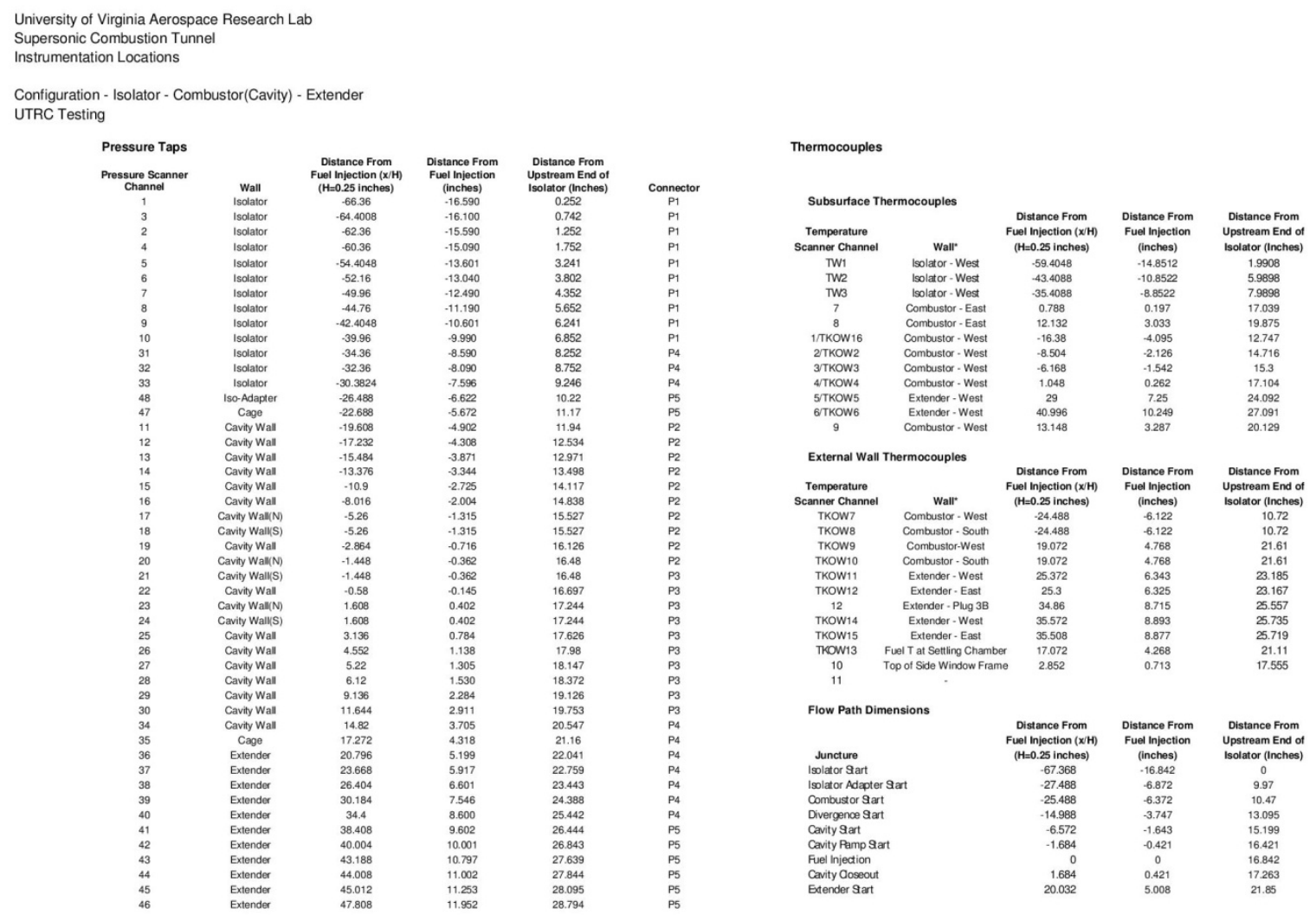

